in a hospital population of all ages the atfection was confined to children between two and sixteen years. No instance of contagion were observed. Its incidence was greatest in the spring, least in the antumm. It was not foumd to show any predilection for weakly children or for cases of oral sepsis. There is nothing characteristic in its probromal svmptoms. There are not two distinct varieties of Vincent's angina. The ulcerative is merely a later stake of the membranous form. Constitutional symptoms are slight or absent, but the local affection is more pronounced than in diphtheria. Association with other diseases is uncommon. The prognosis is farourable. Complications are infrequent and usually insignificant. Treatment consists in the local application of tincture of iodine or methylene-blue powder. Internal medication is usually unnecessary.

Dundas Grent.

\title{
THY ROID.
}

Mumford, J. G.-Grmes" Disease. "Boston Merl. and Surcr. Journ.," June 2, 1911).

The author's conclusions are: (1) Graves' disease is due to abnomal antivity of the thyroid stand. (2) In andrancel cases degenerative changen in the inland may lead to a shifting symptom-complex, ending at list in the positive signs of myxodema. (3) The histologry of the grand in Graves' listase indicates shifting, arlvancing, and retrogratding symptoms. (1) An enlarged thymus is nearly always foumd post-mortem in patients deat of Graves disease (5) Advianced Graves' disease may exist without the presence of all the rlassical srmptoms. (6) The disease can nearly always he ctured if taken early. (7) The sera of Rogers and Beche cure a goonlly percentage of cases. (8) 'Through neutral hydrobromate of quinine, as used by Forchheimer and by Jackson, is foumd a large percentage of improvements and of cures. (9) More than 70 per cent. of patients are cured ly partial thyroidectomy. (10) Treat the case early by rest, by sera and hydrobromate of quinine: if no improvement results in two months operate by thyroidectomy, and always regard the operation as the surest cure.

Macleod Yearsley.

\section{EAR.}

Randall, B. A. (Philalelphia).-How fir is Heredity "Canse of Aurel Disertse? "Amer. Journ. of Meil. Sci.," July, 1910.

The writer deprecates the tendency displaved by some authors to ascriles undue importance to hereditary influences in the causation of ear disteise. Especially in regard to ostosclerosis he considers it very doubtful whether heredity plays the important rile so often assigned to it, and points ont that the proof of grenuine otosclerosis being, even in observed asses, far from positive, must in the unexamined relatives rest almost on pure assumption. He attributes some importance to a special susceptihility of the mucous membrane in some families to catarrhal troubles, and brids that some influence should he ascribed to peculiarities of structural configuration which are certainly inherited. He claims, therefore, that predisposition alone "an fairly be claimed as a factor in the inheritance of car disease, and the denree of this is not likely to be anreed upon by the anthorities.

Thomas Ginthrie. 